\title{
An Experimental Study on Double Basin Solar Still Augmented with Evacuated Tubes And Reflector
}

\author{
Renuka Deshmukh ${ }^{*}$ and K.P. Kolhe \\ Mechanical Engineering Department, SPP University, JSPM'S Imperial college of engineering Wagholi, Pune ,India.
}

Accepted 15 June 2016, Available online 20 June 2016, Special Issue-5 (June 2016)

\begin{abstract}
In this experimental study two basins such as lower basin and upper basin is of size $1000 \mathrm{~mm} \times 330 \mathrm{~mm} \times 380 \mathrm{~mm}$ and $1000 \mathrm{~mm} \times 590 \mathrm{~mm} \times 310 \mathrm{~mm}$ are used. The salted water is used for distillation. Distillation is done by evacuated tubes. Reflector is used to increase the temperature of evacuated tube. Most of the previous research works have been focusing on single basin solar still, flat plate collector and concentrating collector. In this project various temperatures are measured by using different conditions are single basin solar still with evacuated tubes, double basin solar still, double basin solar still with evacuated tubes and reflector. The output of double basin solar still is greater than single basin solar still. This technique is definitely useful for domestic purpose. People who are living in remote areas can use this technique for drinking purpose.
\end{abstract}

Keywords: Double basin solar still, Evacuated tube, Distillate output, Clean potable water, Productivity.

\section{Introduction}

The basic need of human is water. Less than $1 \%$ water is available for human consumption. Today it is very essential to drink clean potable water. Many more functions of our body depend on availability of water in the system. If our body temperature goes above $37^{\circ} \mathrm{C}$ our muscles will boil. So that we have to maintain the body temperature by drinking more water in a day. Minimum 8 to 10 glasses of water should be drink in a day. It is necessary to drink potable water otherwise various diseases will caused. It's a simple procedure to apply at domestic level.

El-Sebaii et al., presented about the water demand increasing day by day because of industrial development, intensified agricultural growth, increase in world population, various improvements in human standards, only $3 \%$ water is clean which available for many other purposes. Fresh water is needed for every purpose like domestic and industrial. The ocean water source is maximum but it is not beneficial for human because lot of salt content in the water.

Therefore it is an essential thing to available maximum clean potable water for the society. It's a need to discover various sources of clean potable water. Hence the distillation technique should develop. Some improvements are done in this project. In recent years some countries are developing about solar water distillation. Distillation can be done by various methods. The brackish water availability is more than clean water.

*Corresponding author: Renuka Deshmukh
Electro dialysis and reverse osmosis are economical for the large systems. A number of solar still units are installed in West-Indian Islands, Saudi Arabia, Mexico and Australia etc for solar distillation. Distillation process is reliable and the cost of the process is very less. Middle class people can afford the cost of unit. Solar energy is available in free of cost than other fuels costing. It is important for the locations where high solar intensity and there is a scarcity of clean potable water. Solar distillation is a process where solar energy is used to distill the clean potable water from salted water for drinking purposes, in charging of the batteries, research laboratories and medical appliances etc.

Rai et al. experimented single basin solar still by various modes with area $1 \mathrm{~m} \times 1 \mathrm{~m}$ and flat plate collector coupled with an angle 450 . From this study found that, with the salt concentration the rate of daily distillate decrease. Surface tension increases by addition of salt and rate of evaporation descreases in a basin. One of the best performance in a single basin still is that a single basin solar still coupled with a flat plate collector having forced circulation and over the basin water blackened jute cloth floating and a small quantity of black dye was used in the water with material of FRP is used, concluded that $50 \%$ more than the thermo-syphon mode, found that distillation rate was increased by $30 \%$ when a small quantity of black dye is adding to the water, $120 \%$ more than the simple single basin solar still. Electricity is used to run the pump. 
Prasad and Tiwari et al, experimentally coupled a compound parabolic concentrator (CPC) to the basin of solar still. In addition thermal energy at higher temperature was fed for production of maximum distilled water. The active solar system is preferred. The final conclusion from the experiment the rate of thermal energy releases from the basin increases with increase in glass cover inclination. Hence, the utilization of glass cover inclination was needed for the maximum output energy. This system can produce 7 lpd from $1 \mathrm{~m} 2$ of solar still basin area and of CPC.

Badran et al. Presented the effect of coupling a flat plate collector with the solar still productivity. A solar Still having the area of $1 \mathrm{mx} 1 \mathrm{~m}$ with collector angle of 350. From the discussion the solar still is having maximum output for the least water depth in the basin is $2 \mathrm{~cm}$, if further increase in water depth will decreased the productivity of still, while the still productivity is to be proportional to the intensity of solar radiation. Insulating material used is Rock wool and having thickness of $6 \mathrm{~cm}, 36 \%$ more than the simple single basin solar still. Maximum distillate with $3.5 \mathrm{l} / \mathrm{m} 2$, Optimum angle for solar still is found to be 100 for winter season in Jordan. Productivity is less compared with forced circulation mode, it is easy for operation. Double slope solar still producing lower yield than simple solar still.

Boukar and Hannim et al., presented the effect of desert climatic conditions compared with coupled to flat plate collector.Different depth levels of brackish water(2.5 to 3.5) are tested under clear sky conditions in a day. The still productivity in summer varied from 4.01 to $4.34 \mathrm{l} / \mathrm{m} 2 / \mathrm{d}$ for simple basin and 8.02 to 8.07 $1 / \mathrm{m} 2 / \mathrm{d}$ for the coupled one. Abdallah et al., presented the use of heat absorbing materials in four identical solar stills. The first three stills which contained uncoated metallic wiry sponge, coated metallic: wiry sponge and black volcanic rocks. The fourth one used as reference still does not contain any absorbing materials (black painted). The results showed that uncoated sponge has the highest water collection during day time, followed by black rocks and then coated metallic wiry sponges. On the other hand, the overall gain in overnight water collection was $28 \%$, $43 \%$ and $60 \%$ for coated and uncoated metallic wiry sponges and black rocks respectively. Badra et al.,[7]studied the thermal performance of a single basin still with single slope coupled with solar collector. The insulation thickness to the still collector is used as $(1,2.5$ and $5 \mathrm{~cm})$. The parameters analysed are solar intensity, overall heat loss coefficient, absorptivity, transmissivity, wind speed, temperature difference between cover and water. The conclusion from this study was overall efficiency was increased by increase in basin water temperature. Hence the distillate output of water increases by circulating hot water from the basin. Singhet al., [8] experimented on single slope solar still integrated with solar water heater during low sunshine or cloudy conditions due to distillation process and concluded that water productivity increased up to $120 \%$ when solar still basin combined with solar water heater and nocturnal (during night) production contributes up to $14 \%$.

Shanmugan et al., enhanced the productivity by attaching booster mirror (acrylic) just above the glass cover of still basin of area $1 \mathrm{~m} 2$. The results obtained with mirror booster the unit output was $4.2 \mathrm{l} / \mathrm{m} 2 / \mathrm{d}$ at $890 \mathrm{~W} / \mathrm{m} 2$ and enhancement was 20 to $26 \%$.

Kabeel et al., experimented about the evaporation and condensation surfaces.This surfacesplay important roles in the performance of basin type solar still. In present study, a concave wick surface was used for evaporation and four sides of a pyramid shaped still were used for condensation. The use of jute wick increased the amount of absorbed solar radiation and enhanced the evaporation surface area. A concave shaped wick surface increases the evaporation area due to the capillary effect. Results showed that average distillate productivity was $4.111 \mathrm{~m} 2 / \mathrm{d}$ and a maximum instantaneous system efficiency of $45 \%$ and average daily efficiency of $30 \%$ were recorded. An estimated cost of 1 litter of distillate was \$ 0.065 for the presented solar still.

Mitesh Patel et al. The solar still basin area of $1 \mathrm{~m}^{2}$ is to be tested with different surface coatings/materials and take performance variation with different sensible heat storage materials black, blue and red dye used inside the brackish water. The test results are to be compared with literature and with \& without absorber media inside the still with different heat and mass transfer coefficients like evaporative, radiative and convective heat transfer. When it is kept in sunlight temperature inside the evacuated glass tube is more than 800C. The experimental set up was analysed by with and without dyes. It has been seen that output with black dye is higher compare to other dyes, while output was lower without dye. The authors found that the distillation output increases slightly when the plate number is over 5 , and it increased by about $34 \%$ and $15 \%$ when the evaporating plate numbers are 1 and 6 , respectively. Collector area of $1.4 \mathrm{~m} 2$, Collector angle of 150.The numbers of evaporative plates are optimized as 5 for the water flow rate is $50 \mathrm{~kg} / \mathrm{h}$. Only few researches have been reported and concluded that. The average distillate water production of $5 \mathrm{~kg} / \mathrm{m} 2$ day was obtained by using 5 numbers of evaporative plates.

The objective of this project is to obtained maximum distilled water by double basin solar still. By this unit the clean potable water is used in the remote areas by using salted water as a input. It requires less floor area and useful in any season. Two basins with double slope is used in the experiment.

\section{Experimental setup and Methodology}

The experimental setup was designed and installed at Nagpur, India. The major elements used in the experimental setup are double basin solar still and evacuated tubes. The experimental setup used for this project is shown in fig 1. 


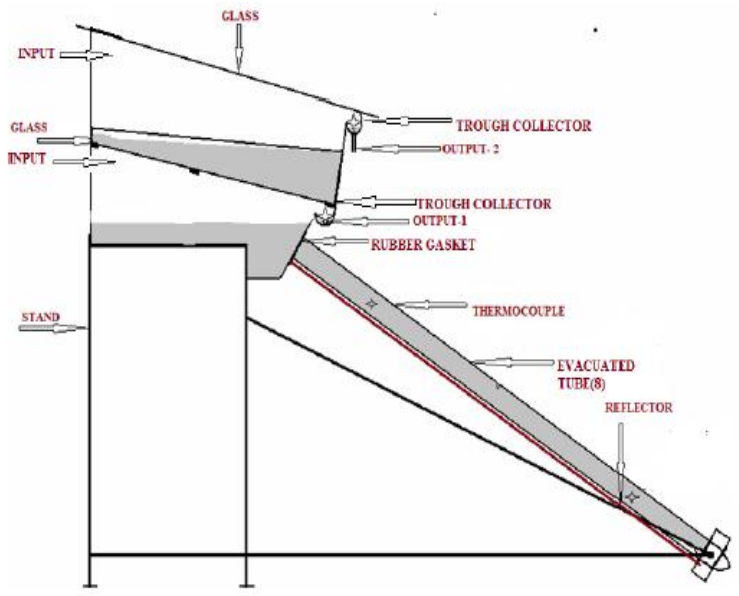

Fig 1. Schematic of the experimental setup

The double basin solar still is made up of mild steel. Basins are painted with black colour. Water is filled in both basins for a height of $15 \mathrm{~cm}$ at the bottom. Less water in the basin increases the temperature of water. Water indicators are provided in both basins. An insulation of $10 \mathrm{~mm}$ thickness is provided at all sides of the basin to reduce the heat losses from basins. Cerawool with the thermal conductivity of $0.12 \mathrm{w} / \mathrm{mkis}$ use for this purpose. The water in the basin is condensed by using an ordinary window glass of size for lower and upper basin is of $1000 \mathrm{~mm} \times 580 \mathrm{~mm}$ and $1000 \mathrm{~mm} \times 600 \mathrm{~mm}$ and the thickness is $5 \mathrm{~mm}$. The purified water condensed from the glass is collected by collecting trough. Collecting trough is in size of $1000 \mathrm{~mm} \times 65 \mathrm{~mm} \times 55 \mathrm{~mm}$. The collecting trough is connected with rubber pipe to collect the distillate water in a jar. A silicon rubber sealant is used to hold the glass intact with the still surface and to prevent the vapour leakages from the still. Holes are made in the upper side of both basin still for the inlet pipe and for the output from the basin. The outlet hole is from collecting trough. Thermocouples are fixed in both basins and for measure/ement of temperature 12 no.Ktype thermocouple is used. Another important part of this project is evacuated tubes. Arrangement of double basin solar still augmented with evacuated tubes is shown in fig. 2. Total 10 no. of evacuated tubes are coupled at lower side. The inner and outer diameter of the evacuated tube is $45 \mathrm{~mm}$ and $48 \mathrm{~mm}$ with the length of $1500 \mathrm{~mm}$ are used for this study. Rubber gasket is used as sealant to prevent the heat losses between the solar still and evacuated glass tubes as well as leakage losses. The evacuated tubes are placed on a metal frame at a height of $1 \mathrm{~m}$ in order to absorb maximum radiations during a day period and it is connected to the still at an angle of $35^{\circ}$ to $37^{\circ}$ with horizontal surface. Reflector plate is made up of Aluminium in corrugated structure are used to increase the reflective radiation falling on evacuated tubes and it is fixed above the metal frame. The bottom end of the evacuated tube is well supported with sponge materials in a separate metal structure of the frame with the height of $0.5 \mathrm{~m}$. The glass of the tube absorbs the solar radiations and it transfers it as heat energy to the water in the tube. Vacuum space between the two glasses reduces the heat losses. The water circulation flows naturally through the single ended tubes. Water in the evacuated tubes is heated by the solar radiation and hot water rises to the still basin due to the density difference. The high temperature water from evacuated tube gets mixed up with the low temperature water in the lower basin still. This makes the low temperature water from the basin to flow back to the evacuated tubes and this process continues.

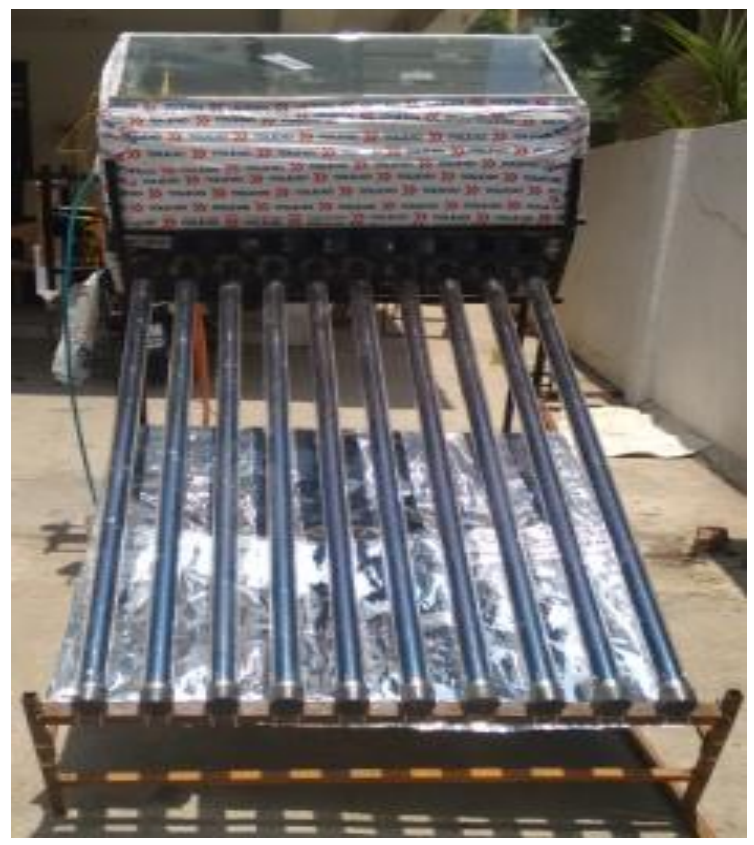

Fig 2. Pictorial view of double basin solar still augmented with evacuated tubes

The wind speed is measured using digital wind anemometer with the range of $0-15 \mathrm{~m} / \mathrm{s}$ and accuracy of $\pm 0.1 \mathrm{~m} / \mathrm{s}$. During the experimental analysis the wind speed measured was in the range of $2-5 \mathrm{~m} / \mathrm{s}$. The temperature of distillation unit at various locations in the still was measured by " $\mathrm{K}$ " type thermocouples with the 12 channels and the range of $0{ }^{\circ} \mathrm{C}-1400{ }^{\circ} \mathrm{C}$ and accuracy of $\pm 1^{\circ} \mathrm{C}$. A plastic measuring jar of $1500 \mathrm{ml}$ capacity is used for the collection of distillate output.

\section{Experimental procedure}

The incident solar radiation is transmitted through an tilted glass cover to the basin water in the upper basin. Thus the upper basin water gets heated up and the evaporation starts. The evaporated water particles condense in the inside layer of the toughened glass cover. This condensed water flows down the cover due to the slope provided and reaches the collecting trough, where it is collected by the collection jar. Water in the lower basin is heated by the water heat loss from upper basin and the heated water from evacuated tubes. Same procedure is done in a lower basin of solar still. At the beginning of the experimental analysis, 
salted water is filled in both basins up to $6 \mathrm{~cm}$ height through the inlet pipe. The experiment is commenced after 24 hours of assembling the glass cover, so as to enable the setup to reach the steady state condition. Daily the experimental analysis starting from morning 9 am to evening $6 \mathrm{pm}$ at hourly intervals. Here these hours are selected because of bright sunshine occurs during such hours. For each experiment glass cover is cleaned to avoid dust collection on the top of glass cover of the outer basin solar still. Here, the experiments have been conducted in the sunny days of May, 2016. The variables measured in the present experiments are Ambient temperature(Ta), Inner basin temperature(Tb1), Outer basin temperature(Tb2), Outer glass cover temperature of the inner basin (Tg1), Outer glass cover temperature of the outer basin(Tg2), Vapour temperature of inner basin(Tv1), Vapour temperature of outer basin(Tv2), Evacuated tube inlet temperature(Tei), Evacuated tube outlet temperature(Teo), Radiation on evacuated tube(I(t)e), Radiation on still(I(t)s), Wind speed(V), Distillate output. Three conditions are experimented through this setup such as single basin solar still with evacuated tubes, double basin solar still with evacuated tubes, double basin solar still with evacuated tubes and reflector.

\section{Result and discussion}

The experiment is carried out for double basin solar still with evacuated tube, Evacuated tube are used to increase temperature of water from starting point to end point because of vacuum present in it which leads to increase rate of evaporation, rate of condensed and increasing the output of basin and productivity of the double basin solar still. The heat loss in lower basin is then transfer to upper basin in order to increase the temperature of upper basin which leads to increase productivity of double basin solar still. The system is operated in a month of May 2016 with clear sun sky of Nagpur, Maharashtra. The main aim of this project is to increase the output of double basin solar still. Temperatures are recorded at different points are shown in following table with the help of $\mathrm{K}$ type thermocouple.

\subsection{Comparison of evacuated tubes inlet and outlet temperature}

The inlet and outlet temperature of evacuated tubes is measured. Inlet temperature is lower than the outlet temperature. At 9am the temperature measured is $39^{\circ} \mathrm{C}$. at $2 \mathrm{pm}$ surrounding temperature reaches maximum so the evacuated tube temperature obtained is $77^{\circ} \mathrm{C}$. after that temperature becomes low slowly. small change in temperature obtained. (Temperature of evacuated tubes measured in ${ }^{\circ} \mathrm{C}$ )
Table1. Temperature of evacuated tube of double basin solar still

\begin{tabular}{|c|c|c|c|c|c|c|c|}
\hline $\begin{array}{c}\text { Sr. } \\
\text { no. }\end{array}$ & $\begin{array}{c}\text { Time } \\
\text { (Hrs) }\end{array}$ & \multicolumn{2}{|c|}{$\begin{array}{c}1^{\text {st }} \text { Evacuated } \\
\text { tube }\end{array}$} & \multicolumn{2}{c|}{$\begin{array}{c}5^{\text {th }} \text { Evacuated } \\
\text { tube }\end{array}$} & \multicolumn{2}{c|}{$\begin{array}{c}10^{\text {th }} \\
\text { Evacuated } \\
\text { tube }\end{array}$} \\
\hline & & Tei & Teo & Tei & Teo & Tei & Teo \\
\hline 1 & $9 \mathrm{am}$ & 39 & 41 & 38 & 40 & 36 & 38 \\
\hline 2 & $10 \mathrm{am}$ & 43 & 45 & 40 & 43 & 40 & 41 \\
\hline 3 & $11 \mathrm{am}$ & 48 & 53 & 46 & 48 & 47 & 53 \\
\hline 4 & $12 \mathrm{pm}$ & 56 & 65 & 55 & 63 & 59 & 62 \\
\hline 5 & $1 \mathrm{pm}$ & 69 & 75 & 69 & 76 & 70 & 73 \\
\hline 6 & $2 \mathrm{pm}$ & 77 & 83 & 78 & 86 & 80 & 89 \\
\hline 7 & $3 \mathrm{pm}$ & 76 & 84 & 79 & 85 & 78 & 83 \\
\hline 8 & $4 \mathrm{pm}$ & 75 & 82 & 76 & 83 & 73 & 79 \\
\hline 9 & $5 \mathrm{pm}$ & 71 & 79 & 70 & 78 & 72 & 75 \\
\hline 10 & $6 \mathrm{pm}$ & 69 & 73 & 64 & 71 & 70 & 71 \\
\hline
\end{tabular}

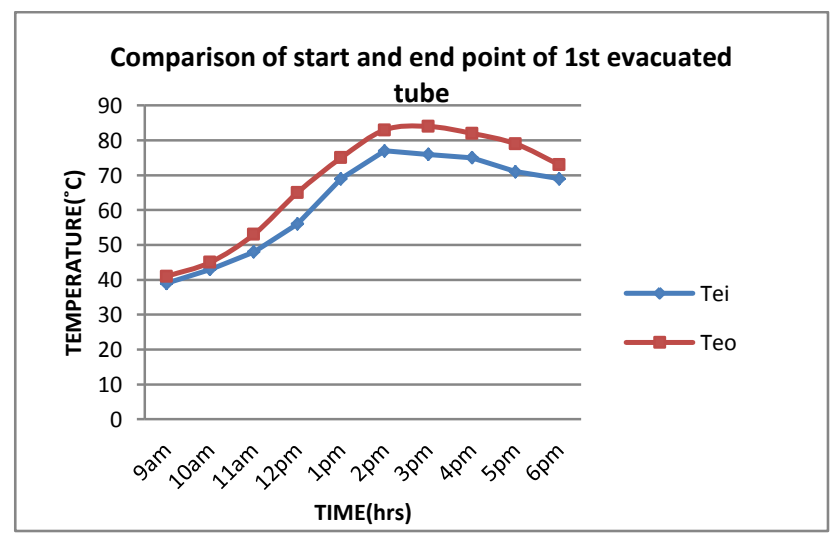

Fig 3. Comparison of evacuated inlet and outlet temperature

The above graph is plotted on the basis of evacuated inlet and outlet temperature.

\subsection{Temperature at various points of distillation unit}

Various point temperature are measured in a distillation unit. Ambient temperature(Ta), Basin temperature(Tb), Glass temperature(Tg), Vapour temperature(Tv), Evacuated inlet temperature(Tei), Evacuated outlet temperature(Teo).

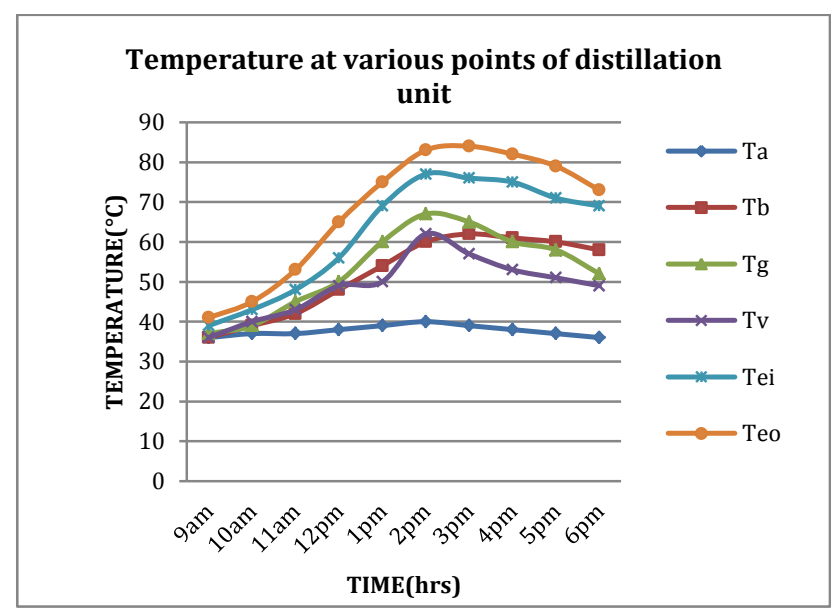

Fig. 4 Temperature at various points of distillation unit 


\subsection{Comparison of distillate output of single and double basin solar still}

Single basin solar still with evacuated tube output is compared with double basin solar still with evacuated tube. Following graph is plotted.

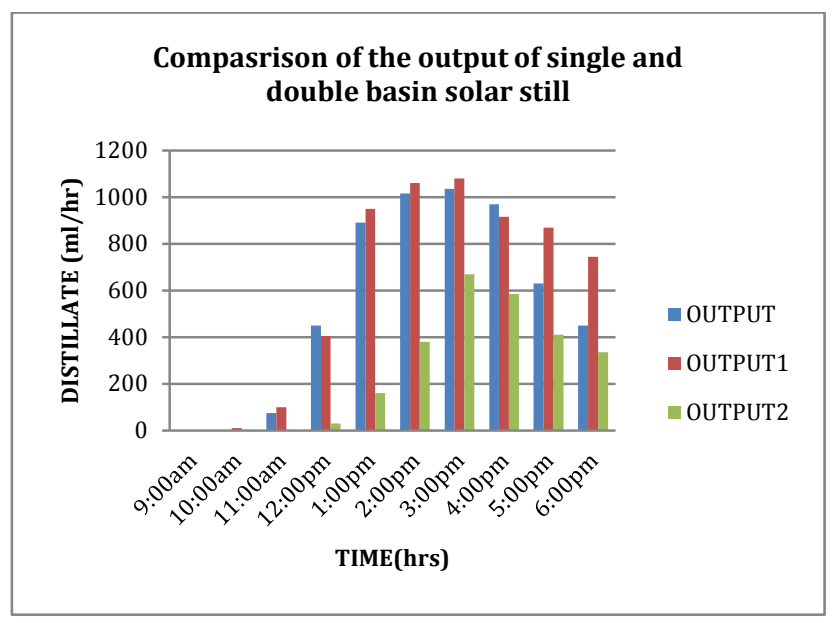

Fig 5.Comparison of the outpout of single and double basin solar still

\subsection{The output of distilled water was tested in laboratory}

The parameters tested in a lab was colour, odour, TDS, turbudity, total hardness,chlorides, alkanity, calcium, magnesium, $\mathrm{pH}$.

$\mathrm{pH}$ value of water is 6.57 .

\section{Economic analysis}

The payback period of the experimental setup depends on the fabrication cost, operating cost maintenance cost, cost of feed water. Whereas cost of feed water is negligible.

Fabrication cost to be considered = Rs. 13000

Operating cost

$=$ Rs. 8/day

Maintenance cost

$=$ Rs. $5 /$ day

Cost of distilled water/lit

$=$ Rs. 10

Productivity of the solar still

$$
=\text { Rs. } 10 / \text { day }
$$

Cost of water produced per day $=$ cost of water/litre $\times$ Productivity

$$
=10 \times 10
$$$$
=\text { Rs. } 100
$$

Net earnings $=$ cost of water produced - maintenance

$$
\begin{aligned}
& =100-5 \\
& =\text { Rs. } 95
\end{aligned}
$$

Payback period = Investment/Net earnings

$$
\begin{aligned}
& =13000 / 95 \\
& =137 \text { days }
\end{aligned}
$$

\section{Conclusions}

Experimental analysis was done for single and double basin solar still in order to increase the percentage of output water. Following observations are found.

1.Amount of water quantity measure for double basin solar still is higher as compare to single basin solar still because of maintaining heat in lower basin of double basin solar still.

2. Minimum $50.8 \%$ and maximum $62.1 \%$ productivity increased by double basin as compare to single basin.

3. Total heat loss from lower basin still is transfer to the upper basin of double basin which increases the productivity.

4. The influence of side insulation is significant on the rate of water production, and the temperature remains same at $3 \mathrm{pm}$. Minute change obtained in the decrease in temperature

5.Maximum output is obtained by connecting reflector with evacuated tube.

6. It is easy and very convenient process of distillation.

7. The payback period was determined to be 137 days.

\section{References}

El-Sebaii A.A., Yaghmour S.J., Al-Hazmi F.S., Faidah A. S., AlMarzouki F.M. and Al-Ghamdi A.A., (2009),Active single basin solar still with a sensible storage medium, Desalination, 249, pp.699-706.

Rai SN, Tiwari GN. (1983),Single basin solar still coupled with flat plate collector, Energy Conversion and Management 23(3):145-9.

Bhagwan Prasad and G. N. Tiwarl,(1996), Effect of glass cover inclination and solar distillation system parametric studies of concentrator-assisted, International journal of energy research, Vol. 20, pp. 495-505.

Badran 00, Al-Tahaineh HA. (2005), The effect of coupling a flat plate collector on the solar still productivity, Desalination; 183:137-42.

Boukar M. and Harmim A.,(2001) Effect of climatic conditions on the performance of a simple basin solar still: a comparative study, Desalination, 137,pp. 15-22.

Abdallah S, Abu-Khader M M and Badran 0,(2009) Effect of various absorbing materials on the thermal performance of solar stills, Desalination, 242, 128- 137.

Badra 0,(2011) Theoretical analysis of solar distillation using active solar still, International Journal of Thermal and Environmental Engineering, 3 (2), pp. 113-120.

BhanuPratap Singh, (2011)Performance Evaluation of a Integrated Single Slope Solar Still With Solar Water Heater, MIT International Journal of Mechanical Engineering Vol. 1 No. 1 , pp. 68-71.

S. Shanmugan, P. Rajamohan and D. Mutharasu, (2008) Performance study on an acrylic mirror boosted solar distillation, Desalination 230, pp. 281- 287.

Kabeel A E,(2009) Performance of solar still with a concave wick evaporation surface, Energy, 34, pp. 1504-1509

Miteshpatel, P.M.Meena,Sunil Inkia,2011 ,Experimental investigation on single slope double basin active solar still coupled with evacuated glass tubes,IJAERS,2249-8974. 